Hans-Johann Glock

Institute of Philosophy

University of Zurich
Original Scientific Paper

UDK 14 Витгенштајн Л.

164.02 Витгенштајн Л.

81'37:165 Витгенштајн Л.

\title{
MEANING AND METHOD
}

Linguistic meaning (Bedeutung) occupies a central role in Wittgenstein's work, throughout its various evolutions and revolutions. Meaning is the philosophically most important-interesting and puzzling-aspect of language. Now, any subject X can turn into a topic of philosophical reflection and thus precipitate a philosophy of $\mathrm{X}$. But the concern with some topics is central to philosophy. Language is one of them. From Wittgenstein's perspective, its perennial importance has three distinct though related roots. First, there is the anthropological dimension. Philosophy is interested in language because of the latter's 'paramount role in human life' (BT 194-5, 413). Language is crucial to sustaining specifically human forms of communication and interaction. Secondly, there is the vexed relation between thought and language. There is an internal connection between thought and its linguistic expression. Language is not just a secondary means of expressing and communicating non- or pre-linguistic thoughts, it is its indispensable vehicle or medium. Qua rational beings, humans are therefore at the same time essentially language-using animals. Thirdly, there is the metaphilosophical connection. Philosophical problems, by contrast to those of science, arise not out of factual ignorance about reality, but out of confusions concerning the language in terms of which the problems are posed. In this sense, philosophical problems, claims, arguments and theories, by contrast to those of science, concern or are rooted in language rather than reality. For the a priori nature of philosophical questions and the necessary status traditionally claimed for philosophical propositions are to be explained by reference to linguistic rules. More specifically, the rules in question are semantic rules, rules which are constitutive of the meaning of expressions. As a result, Wittgenstein's thought revolves around issues of meaning, both as regards its metaphilosophical claims and as regards its philosophical practice.

My essay discusses the dynamic interaction between linguistic meaning and philosophical method. On the one hand, Wittgenstein's method relies on a certain conception of meaning and its connection to a priori problems and necessary propositions; on the other hand, this conception of meaning is shaped by his ideas about how philosophy ought to be done. At the end of this article I address the question whether this amounts to a vicious circularity that undermines Wittgenstein's later approach to philosophy. My 
answer is that Wittgenstein's approach is defensible, but only if one abandons the misguided aspiration of establishing the proper philosophical method in a presuppositionless way.

\section{Meaning and Philosophy in the Tractatus}

No philosopher since Kant has thought as hard about the nature of the subject as Wittgenstein.

The Tractatus is devoted to two major themes, the essence of representation or intentionality on the one hand, the nature of logic and philosophy on the other. The two are interrelated. Wittgenstein followed Russell in identifying philosophy with the logical analysis of propositions. Furthermore, in the spirit of Kant's 'transcendental logic' he held that logic comprises the most general preconditions for the possibility of representation. We represent reality through thought. But the Tractatus breaks with the traditional view that language is merely a medium for transmitting pre-linguistic thoughts. Thought is intrinsically linked to the linguistic expression of thought (TLP 3, 3.1, 3.5, 4; see also PI $\$ \$ 329-30$ ). Wittgenstein's first master-piece features a striking account of the essence of symbolic representation-the picture theory of the proposition-which at the same time furnishes a metaphysical account of the basic constituents of reality-logical atomism-a novel understanding of logic, and a revolutionary conception of philosophy itself. All meaningful propositions can be analyzed into logically independent 'elementary propositions. The ultimate constituents of such propositions are unanalyzable 'names' (the simplest components of language). These names have as their meaning, i.e. stand for, indestructible 'objects' (the simplest components of reality). An elementary proposition depicts a possible combination of objects-a possible 'state of affairs' - by arranging names in a certain manner. If that possible state of affairs actually obtains, that proposition is true.

Empirical propositions have sense by virtue of depicting possible states of affairs. They are 'bipolar', capable of being true, but also capable of being false. By contrast, logical propositions lack sense. They are vacuous 'tautologies', since they combine empirical propositions in such a way that all factual information cancels out. 'It is raining' says something about the weather-true or false-and so does 'It is not raining. But 'Either it is raining or it is not raining' does not (TLP 4.461). The necessity of tautologies simply reflects the fact that they do not make any claims the truth-value of which depends on how things actually are.

Finally, the pronouncements of metaphysics are not just senseless but 'nonsensical'. They are 'pseudo-propositions' which try to say what could not be otherwise, e.g., that red is a colour, or 1 a number. What they seem to exclude-e.g. red being a sound-contravenes logic, and is hence nonsensical. 'Most of the propositions and questions to be found in philosophical 
works are not false but nonsensical' (TLP 4.003). On the other hand, what such metaphysical 'pseudo-propositions' try to say is shown by empirical propositions properly analyzed. In fact, the pronouncements of the Tractatus itself are in the end condemned as nonsensical. They lead one to appreciate the essence of symbolic representation. Once this is achieved, however, one must throw away the ladder which one has climbed up (TLP 7).

The Tractatus heralded the linguistic turn of twentieth century analytic philosophy. Metaphysics poses pseudo-questions that admit of no answer. The proper task of philosophy is not to answer these questions but to show that they violate the bounds of sense. 'All philosophy is a "critique of language" (TLP 4.0031). Philosophy is not a 'doctrine', since there cannot be philosophical-a priori and necessary-propositions with a sense. It is an 'activity', a 'critique of language' by means of logical analysis. Positively, it elucidates the meaningful propositions of science; negatively, it reveals that metaphysical statements are nonsensical (TLP 4.0031, 4.112, 6.53f.).

The correct method of philosophy would actually be the following: to say nothing except what can be said, that is propositions of natural science-that is, something which has nothing to do with philosophy - and then, whenever someone else wanted to say something metaphysical to demonstrate to him that he had failed to give meaning to certain signs in his sentences (TLP 6.53; my transl. and emphasis).

Accordingly, semantic notions play a central methodological role in the Tractatus, albeit a critical one. They also feature in its positive account of the relation between language and reality which motivates the early Wittgenstein's conception of philosophy, the so-called picture theory of the proposition (see Glock 2006). Like Frege, Wittgenstein distinguished between sense (Sinn) and meaning (Bedeutung). Unlike Frege, he recognized that there is a crucial difference between names (and words more generally) on the one hand, propositions on the other. Propositions are not names; they do not refer to (bedeuten) a truth-value (Frege); nor do they stand for a fact (Moore). Conversely, simple names go proxy for objects directly, without the mediation of a sense (description). As a result, the Tractatus maintains that names have a meaning but no sense, while propositions have a sense but no meaning (TLP $3.142,3.203,3.3)$. The sense of an elementary proposition is the state of affairs it depicts, and it is a function of the meanings of its constituent names, this being one reason why the logical structure of language has to pay heed to the metaphysical constitution of reality.

It is clear, therefore, that the Tractatus was intimately concerned with linguistic meaning. It is all the more ironical, therefore, that the book put semantics on the index. For would-be statements about the essential preconditions that a system of signs must fulfill to depict reality would be necessarily true. They would thereby fall foul of the criterion of sense 
implicit in the picture theory, according to which only bipolar propositions have a sense. As a result, the things which cannot be 'said', i.e. expressed by propositions with a sense, include the meaning of signs and that two signs have the same meaning (TLP 3.33/2, 6.23), what a given symbol signifies (TLP 4.126 ), and the sense of a proposition (TLP 4.022, 2.221). At the same time these things can be 'shown': they reveal themselves in bipolar propositions with a sense, provided that the latter are properly analyzed.

\section{Meaning and Philosophy in the Later Work}

On his return to philosophy from 1929 onwards, Wittgenstein took this linguistic turn in a different direction. As before, he regarded philosophy as an activity striving for clarity rather than a cognitive discipline resulting in theories or knowledge (LWL 1; AWL 225; RPP I \$115). At the same time, he abandoned the idea that the essential features of reality that traditional metaphysics tried to 'say' something about can be shown through analyzing empirical propositions. And he replaced the mere promise of critical analysis by an elaborate and sophisticated dialectic practice. Philosophy dissolves the conceptual confusions to which philosophical problems are alleged to owe their existence.

This non-cognitivist picture appears to impoverish philosophy, and is generally considered to be the weakest part of Wittgenstein's later workslogans unsupported by argument and belied by his own positive 'theory construction' which can be isolated from the rest (e.g. Dummett 1978, p. 434). In fact, however, the impression that Wittgenstein's methodological views are unsupported by argument arises from failure to recognize the connections which hold, firstly, between various aspects of his conception and, secondly, between his conception of philosophy as a whole and other parts of his later philosophy, notably his account of logical necessity and his understanding of language or grammar. Indeed, they arise from a coherent line of thought that can be reconstructed along the following steps:

A) Philosophy differs in principle from the sciences because of the $a$ priori character of its problems.

B) Properly conceived, a priori propositions do not depict necessary states of affairs. Instead, they are 'grammatical propositions' that express 'grammatical rules' for the use of expressions. For the meaning of expressions and thereby our concepts are determined by such rules. As a result, philosophy is a second-order enterprise: instead of describing and explaining reality it is concerned with the 'grammar' that constitutes our conceptual scheme.

C) These rules are not responsible to an 'essence of reality'; therefore, philosophy has no license to justify or reform our conceptual scheme on 
metaphysical grounds, it can only explicate that scheme by describing our linguistic practices.

D) These descriptions cannot take the form of discoveries, theoryconstruction or decompositional analysis. They remind us of how we actually speak when we are not in the grip of philosophical puzzlement, of grammatical rules we are already familiar with as competent speakers.

E) Consequently, the main (though not necessarily sole) purpose of grammatical investigations and thereby of philosophy is critical and to that extent negative.

F) This critique is neither systematic nor does it make progress in the way science does.

In the next section I shall dwell briefly on (A) and at greater length on (B), the reason why philosophy is concerned with meaning. ${ }^{1}$ The following sections turn to Wittgenstein's conception of meaning, and how it is shaped by his metaphilosophical views and his philosophical method.

\section{Why Philosophy is Concerned with Meaning}

In Wittgenstein's later work, matters of meaning are of paramount importance, not just implicitly but officially. He even declared the 'transition from the question of truth to the question of meaning' (MS 106, p. 46) to be central to his philosophical method. This is as clear and succinct a proclamation of the linguistic turn as one could wish for. Unlike its precursor TLP 4.0031 it explicitly makes the meaning of expressions central to philosophy. Philosophy is not in the business of establishing truths about reality, but of clarifying the meaning of those expressions which give rise to conceptual confusions and thereby to philosophical puzzlement.

Concerning (A), Wittgenstein insists, against empiricism and naturalism, that philosophy is a priori (LWL 79-80; AWL 3, 97, 205). Philosophical problems cannot be solved simply by empirical observation or scientific experiment. For they are conceptual rather than factual ( $\mathrm{Z} \$ 458$; CV 79). They ultimately concern concepts mastery of which is a precondition of establishing new empirical facts; at the same time, such mastery does not guarantee the kind of comprehension required to avoid philosophical puzzlement (PI $\$ 89$; see $\$ \$ 95,428$; BB $30-1$; BT 435 ; RPP II $\$ 289$; CV 4). Our concepts can change as a result of novel empirical discoveries; yet these will not resolve the problems arising out of the concepts prior to such conceptual change.

Turning to (B), our conceptual scheme is embodied in our language. More specifically, although concepts cannot simply be equated with 'meanings', to

1 For a sustained discussion of (A)-(F) see Glock 2017b. 
specify what general terms like 'mind', 'thinks' or 'is conscious' mean is to specify what concepts they express, and vice versa. Consequently, to clarify the concepts expressed by our terms is to establish what these terms mean. And to do that is to articulate the rules of use that determine what expressions mean (see PI \$\$381-3). What Wittgenstein (misleadingly) calls the 'grammar' of a language is not confined to morphology and syntax; it is the overall system of logico-semantic rules, of the constitutive rules which determine what it makes sense to say in it (PR 51; LWL 46-59; PG 60, 133, 143; PI \$496). Therefore, explicating our concepts and thereby our 'form of representation' takes the form of articulating semantic rules through grammatical propositions.

By determining what expressions mean, grammatical rules also hold the key to understanding apriority and necessity. Grammatical propositions antecede experience in an innocuous sense (PR 143; LWL 12; AWL 90). They can neither be confirmed nor confuted by experience. 'Black is darker than white, for instance, cannot be overthrown by the putative statement 'This white object is darker than that black object', since in established usage nothing counts as being both white and darker than black. This antecedence to experience renders intelligible the apparently mysterious 'hardness' of necessary propositions (PI \$437; RFM I \$121; PG 126-7). To say that it is logically impossible for a white object to be darker than a black one is to say that given our semantic rules, it makes no sense to apply 'white' and 'darker than black' to one and the same object.

\section{A Use Theory of Meaning?!}

The later Wittgenstein did not just complete the linguistic turn. He also revolutionized analytic philosophy by following through another incipient idea of the Tractatus. It concluded the latter's partial move away from a referential conception of meaning. According to this conception every meaningful expression stands for an object, the latter being its meaning. Wittgenstein's main objections match the simplicity, if not the simplemindedness, of this target.

Not all meaningful words refer to objects. The referential conception is modelled mainly on proper names, mass nouns, and sortal nouns. It ignores verbs, adjectives, adverbs, connectives, prepositions, indexicals, and exclamations (PI $\$ \$ 1-64)$. Moreover, even in the case of referring expressions, their meaning is not the object they stand for. If the meaning of a word were an object it stands for, referential failure would have to render a proposition like 'Mr. N.N. died' senseless (PI \$40).

Finally, Wittgenstein presented a famous alternative to the referential conception. 'For a large class of cases-though not for all-in which we employ the word 'meaning' it can be defined thus: the meaning of a word is 
its use in the language' (PI $\$ 43$ ). This famous passage is perplexing, especially as regards the restriction. If it applies to 'the meaning of a word', it is unclear either what kinds of meaning or what types of words are excluded. For better or worse, Wittgenstein had no qualms about ascribing meaning e.g. to proper names (e.g. PI $\$ \$ 40-2,79$ ). If the restriction applies to kinds of meaning rather than kinds of expressions, then Wittgenstein might have had in mind certain senses of 'meaning', notably natural significance as in 'These clouds mean rain', teleological significance as in 'the meaning of life' and speaker's meaning. The reference to 'use in a language' shows that PI $\$ 43$ is concerned with the lexical meaning of type-expressions in a language. By contrast, PI $\$ \$ 432$ and 454 appear to concern speaker's meaning. In the sequel, I shall first focus on lexical meaning. Speaker's meaning will make an appearance at the end, however. For both phenomena are important to Wittgenstein's philosophical methodology, that is, in his metaphilosophical claims and in his actual philosophical practice.

Wittgenstein's dicta on meaning and use are often taken to evince a 'use theory of meaning. But Wittgenstein explicitly denied that philosophy should be in the business of constructing theories. Moreover, he was notoriously sceptical about 'What-is ...?' questions in general. Finally, his slogan 'Don't ask for the meaning, ask for the use!' can be read as an attempt to circumvent the question 'What is meaning?' in particular. I shall resolve this tension as regards its substantive though not its exegetical dimension. Wittgenstein's ambivalence and the proclivities of many of his followers notwithstanding, there is no merit in avoiding our title question. Fortunately, while Wittgenstein's reflections do not amount to a theory of meaning in the sense popularized by formal semantics, they suggest a viable account of the concept of linguistic meaning, namely through highlighting its connections with other concepts like those of rule, explanation and understanding.

The basic idea of a use theory is this: the meaning of an expression $e$ is not a bona fide object-whether physical, mental or abstract-for which it stands; it is rather the use competent speakers make of $e^{2}$ The idea that meaning is use not only informs-often implicitly-the philosophy of Wittgenstein and post-war conceptual analysis, it is also accepted by some of their opponents, notably Quine (1981, Chapter 5) and Dummett (1993b). It has often been taken for granted by field-linguists (e.g. Crystal 1987, p. 102) and is currently defended by eminent philosophers of language like Horwich (2005). Indeed, it is one of the few Wittgensteinian dicta which are immediately plausible (see below). Nevertheless, the claim that meaning is use has invited vigorous criticism from highly diverse angles. Sometimes Wittgenstein's followers try to bypass the latter $a b$ initio by pointing out that he does not proffer a theory of meaning. This is correct, yet it does not immunize his remarks on meaning

2 Unless otherwise specified (see Section 12), the variable ' $e$ ' ranges over linguistic expressions, including both sentences and their components; simplifying, I shall refer to the latter as 'words'. 
against criticism. Wittgenstein and other conceptual analysts profess to investigate the meaning of words. This presupposes a conception of meaning. Furthermore, that conception must at least allow of being spelled out in a coherent fashion, and hence of furnishing an account of meaning. This holds all the more so if philosophical investigations of meaning are contrasted with systematic theories (see Dummett 1993a, Chapter 14; compare Hanfling 2000 , pp. 42-8). Whether meaning is the sort of thing one should have a theory about depends on the concept of meaning. It also depends on what is meant by a 'theory' in this context.

Traditionally, a theory of meaning was supposed to provide an analysisin a suitably loose sense-of the concept of meaning and related notions. Theories of meaning in this 'analytic' sense include the referential theory, behaviorist and causal theories like that of Quine, verificationist theories, speech-act theories influenced by Austin, Grice's theory of communication intentions. They also include Wittgensteinian accounts of meaning as use. These enterprises are theoretical only in a minimal sense. They provide more or less sustained and orderly accounts of the concept of meaning, as well as arguments in their support.

By contrast, in the wake of Davidson, formal semantics envisages a 'constructive' theory, notably for natural languages. Such a theory does not directly explain what meaning is. Instead, it generates for each actual or potential sentence $s$ of a particular language a theorem 'that, in some way yet to be made clear, "gives the meaning" of $s$, and shows in particular how that meaning depends on that of its components (Davidson 1984, p. 23). Analytic theories of meaning should be compatible with the way the meaning of particular sentences is specified or explained. Yet unlike constructive theories they do not prescribe an algorithm for generating such specifications (see Glock 2003, pp. 141, 152-3).

Now, it is obvious that Wittgenstein's conception of language is inimical to the very project of a constructive theory of meaning (see Baker and Hacker 1984). He also denied that theories had a role to play in philosophy. Arguably, however, that denial is based on an unduly narrow conception, which confines theories to those conforming to the hypothetico-deductive model supposed to characterize theories in the natural sciences (PI \$109; cp. Hanfling 2004; Glock 2017, pp. 245-6). One might defend PI $\$ 109$ on the grounds that any theory worthy of the name must provide explanations of its topic. But although Wittgenstein bans causal explanations philosophy, he insists that explanations of meaning have a role to play (see, e.g., LWL 38; PG 70; PI $\$ \$ 69-71,75,120,339$ and below). Furthermore, the substantive issue is whether linguistic meaning allows for or demands a theory in either a minimal or a more demanding sense, and what contribution constructive theories might make. Answering those questions requires an understanding of the concept of meaning that is philosophically serviceable, and thereby what I have called an analytic theory. 


\section{5. 'What is ...?'-Questions}

Ever since Socrates, philosophers have been concerned with 'What is X?' and 'What are Xs?' questions, e.g. 'What is justice?', 'What is knowledge?', 'What is truth?' In response to these questions, they have traditionally sought analytic definitions of X(s). Such definitions specify conditions or features which are individually necessary and jointly sufficient for being X. Furthermore, these features should not just in fact be possessed by all and only things that are $\mathrm{X}$; rather, only things possessing all of the defining features can be $\mathrm{X}$, and anything possessing them all is ipso facto $\mathrm{X}$.

Wittgenstein was adverse to 'What is ...?'-questions as posed in philosophy. Indeed, he suspected them-our title question explicitly included—of inducing a 'mental cramp' (BB 1). There are several important lessons to be drawn from his reservations; yet none of them disqualifies 'What is ...?'-questions per se or in general. First, we ought to shed the essentialist prejudice that one can clarify a concept only by providing an analytic definition (e.g. PI $\$ \$ 64-88$; PG 119-20). Many philosophically important notions defy analytic definition. Fortunately, however, there are other respectable ways of explaining concepts, notably contextual, recursive and ostensive definitions, surveys of family resemblances and explanations by exemplification.

Secondly, we must avoid the Socratic mistake of thinking that a castiron definition of ' $\mathrm{X}$ ' is needed in advance of further investigations (see TS 302, p. 14; PG 121-2), whether they be empirical theory-formation about the phenomenon $\mathrm{X}$ or philosophical reflection on the concept of X. On the other hand, we do need a grasp of what topic we are addressing. This requires at least a preliminary understanding of the meaning of ' $\mathrm{X}$ ', an understanding subject to critical elucidation in philosophical reflection and modification in scientific theory-building. Small wonder, then, that Wittgenstein willy-nilly gave or suggested numerous answers to Socratic questions. By no means all of them are hedged with qualifications; and 'What is meaning?', along with related queries like 'What is understanding?', is very much included. Indeed, such a procedure is a prerequisite for dissolving or avoiding questions and theories of the metaphysical kind Wittgenstein regarded as misleading or confused.

Thirdly, some 'What is ...?'-questions are best addressed through pondering related questions rather than head on. As we shall see, such an indirect approach is crucial to a tenable use theory of meaning.

Still, setting out deliberately to answer 'What is ...?'-questions with their hoary complications and multiple repercussions remains alien to a strand in Wittgenstein's later thinking.

If one describes simple language-games to illustrate, let's say, what we call the 'motive' of an action, one will repeatedly be confronted with more complex (verwickelten) cases, in order to show that our theory 
does not yet conform to (entspricht) the facts. Whereas more complex cases simply are more complicated cases. To wit, if a theory were at issue, one could indeed say: there is no use in regarding these special cases, they do not provide an explanation exactly of the most important cases. By contrast, the simple language-games play an entirely different role. They are poles of a description, not the basis (Grundstock) of a theory (RPP I \$633).

As is his wont, Wittgenstein puts his finger on the crux of the matter. Unfortunately, his verdict is unwarranted. More complex cases need not occasion throwing up one's arms in despair. Nor do they license shrugging one's shoulders in the vain hope that exclusive contemplation of simple cases by itself will somehow resolve philosophical problems notorious for their complexity, e.g. through a mysterious kind of cathartic 'aspect change' or intellectual vision. Instead, more complex cases do indeed provide reasons for adjusting our 'theory'-i.e. analysis or explanation. We are called upon to fit the pieces of the conceptual jigsaw puzzle together. In this respect, conceptual analysts like Ryle, Austin and Strawson have the edge over Wittgenstein and many of his disciples. Note, however, that Wittgenstein himself counselled 'the quiet weighing of linguistic facts', namely as an antidote to 'turbulent speculation’ of a metaphysical kind ( $\mathrm{Z} \$ 447$; see also AWL 48).

There is no philosophical point in being squeamish about 'What is ...?'-questions. After all, both Wittgenstein and conceptual analysts purport to resolve philosophical problems by elucidating the concepts in terms of which they are phrased. Next, although concepts cannot simply be equated with 'meanings', to specify what general terms like 'mind', 'thinks' or 'is conscious' mean is to specify what concepts they express, and vice versa (see Glock 2010, pp. 312-5). As a consequence, they are committed to a stance on 'What is X?'-questions, provided that these are understood as inquiries into the concept of $\mathrm{X}$ rather than scientific questions into what $\mathrm{X}(\mathrm{s})$ are like. By contrast, throwing in the towel and reveling in the diversity and alleged chaos of our linguistic practices can never be more than a last resort.

\section{Eliminativism about 'Meaning'}

Even if one leaves aside blanket qualms about 'What is ...?'-questions, one may feel no need to answer this question as regards meaning in particular. One can take the shortcomings of referential conceptions as an argument not in favor of a use theory, but of the view that the notion of meaning is misleading and obsolete.

Once again, one might invoke Wittgenstein's authority in support of this strategy of avoidance. He was fond of counselling: 'Don't ask for the meaning, ask for the use!' This slogan appears to manifest a downright refusal to engage with the nature of meaning. According to this interpretation, Wittgenstein 
does not provide even an account of meaning, in linking meaning and use he was simply giving a piece of methodological advice. In investigating philosophically contentious terms the very notion 'the meaning' misleads us, since its nominal form suggests an object beyond the sign (this is even more obvious for Bedeutung, which derives from deuten, i.e. 'pointing'). The concept of meaning is obsolete save for expressions as 'means the same' or 'has no meaning' (M 51-2; AWL 30; PG 56; PI \$120).

A similar line was taken by Quine. He rejected the idea of mental or abstract meanings as 'the myth of a museum in which the exhibits are meanings and the labels are words' (1969, p. 27). That an expression is meaningful is not due to it being associated with an object which is its meaning. Rather, the 'useful ways in which people ordinarily talk about meanings boil down to two: the having of meanings, which is significance, and sameness of meaning, or synonymy... But the explanatory value of special irreducible intermediary entities called meanings is surely illusory' (1953, p. 11).

Warnings that the concept of meaning carries risks of reification are well taken. Nonetheless semantic eliminativism is doomed. We need at least a notion of linguistic meaning. This holds both for everyday life, where the notion of meaning serves to enable, facilitate and explain crucial aspects of linguistic communication, both within and across linguistic communities. It also holds for successful, semantically clear and epistemically controlled disciplines like formal logic, linguistics, parts of cognitive science, intellectual history, jurisprudence and at least certain branches of philosophy.

Not coincidentally, Wittgenstein continued to operate with the notion of meaning. More specifically, in line with the Tractatus he continued to write of the Bedeutung of words and the Sinn of sentences. Quine for his part availed himself of a behaviourist Ersatz, 'stimulus meaning.' But this marks a point at which the agreement between them ends. For neither outright eliminativism nor replacement by a more or less remote substitute is compatible with Wittgenstein's methodology.

Replacing or modifying philosophically troublesome expressions like 'meaning' by a 'logical explication' à la Carnap or Quine will merely sweep the problems under the carpet, unless the explicatum is properly understood. Once we have elucidated the established concepts, we no longer require an artificial one (PI \$130; Strawson 1963), unless the established concepts were semantically inadequate (obscure, incoherent). But if so, how could we introduce better ones? For these perforce need to be explained in terms already understood, ultimately in ordinary terms of a mother tongue (PI $\$ 120$; Strawson 1992, pp. 10-16). Even if intensional notions like meaning could be explained in established extensional terms, or in terms less liable to tempt us into reifying 'meanings', elucidating the established notion would remain a propaedeutic precondition for logical explication. 
Nevertheless, the numerous paradoxes and antinomies blighting philosophy show that some would-be concepts turn out to be incoherent. This holds for some concepts implicated in set-theoretic and semantic paradoxes (e.g. the purported significata of expressions like 'heterological' or 'the set of all sets that are not members of themselves'). Arguably it also holds for the concept of God as conceived by traditional monotheism, the concept of free will as conceived by libertarians, the concept of a self as conceived by German Idealism, and the concept of a quale as conceived by contemporary philosophers of mind. Yet even if the corresponding expressions should no longer be used (as opposed to mentioned) for cognitive purposes, that drastic step must be preceded by clarification. We need to know at least what the expressions earmarked for elimination purport to mean and what role they were supposed to fulfil. Mutatis mutandis for methodological maxims like 'Don't ask for the meaning, ask for the use!' They had better be based on a clear understanding of the concepts involved. For methods are cognitive instruments accountable to the topics to which they are applied - in our case the philosophically contested notions of meaning and of use.

\section{Meaning, Use and Rules}

Wittgensteinian strategies for evading an investigation of the concept of meaning are unprepossessing. There is no licence for shirking the question of how the meaning of an expression is related to its use, if conceptualcum-semantic questions are tackled by investigating the use of the pertinent expressions. At the same time, many critics of the idea that meaning is use go astray in ignoring the fact that the pertinent concept of meaning is the one used in everyday parlance and in studies of language such as dictionaries and non-formal branches of linguistics, rather than the new-fangled concepts they may have introduced for diverse reasons, even if some of those reasons are sound. My use theory is to be measured against the same standard, namely whether its analysis of 'meaning' and of related terms conforms to the way in which they are used, explained and understood by competent speakers.

There are indeed striking connections between the established concept of meaning and linguistic use:

- whether an expression like 'sesquipedalian' means something in a given language depends on whether it has an established use in the linguistic community;

- what an expression means depends on how it can be used within that community;

- we learn what an expression means by learning how to use it, just as we learn how to play chess not by associating the pieces with objects, but (initially) by learning how they can be moved. 
Arguably, the identification of meaning with use is untenable (Rundle 1990, Chapters 1 and 9 to 10; but cf. the spirited defense in Schroeder 2006, pp. 168-81). However, while some passages (PI \$30, 138; PG 60; LFM 192) appear to identify meaning and use, others stop short of doing so (e.g. PI $\$ \$ 43$, 139). Advisedly so! Although the notions of meaning and of use overlap, they diverge in important respects. Some of these differences are accommodated by keeping in mind the contrast between use in the sense of 'employment of a sign-token' and use as 'way of using' or 'manner of use' (OC \$61); as well as Ryle's parallel distinction of 'use' and 'usage' (1971, ch. 31). The semantically relevant notion of use is that of a way of using a type-expression, its method of employment. By contrast, usage is constituted by the prevalence or nonprevalence of this method of employment in a certain linguistic community. While certain social pressures shape usage, it lacks at least one normative dimension of use: there is the misuse of expressions, but there is no such thing as the 'misusage' of an expression.

Another step towards aligning use with meaning also revolves around normativity. We must avoid reducing linguistic use to a causal process between speakers and hearers after the fashion of causal and behaviorist theories. The meaning of a type-expression does not depend on the actual causes or the actual effects of uttering a token of it, either on a particular occasion or in general (pace causal and behaviorist theories). Nor does it depend on the effects intended by the speaker, however complex and highorder they may be (the Gricean programme notwithstanding).

Suppose I tell you 'Milk me sugar!' This may well have the result that you stare at me and gape. Yet it obviously does not follow that this combination of words means 'Stare at me and gape!' It does not follow if this amusing effect can be repeated. Indeed, it does not even follow if I utter these words with the intention of bringing about this reaction (PI $\$ \$ 493-498$ ). Meaning is a matter not of how an expression is actually used and understood, but of how it is or ought to be used and understood by members of a linguistic community. What is semantically relevant is the correct use of expressions. ${ }^{3}$ This also puts paid to the popular yet short-sighted objection that meaning cannot depend on use because speakers frequently misuse expressions. Summarizing this normativist conception of use, the later Wittgenstein maintained that the linguistic meaning of an expression is 'constituted', 'determined' or 'given by' rules which lay down how it is to be used correctly (see M 51; PG 62-4; OC $\$ \$ 61-62$; LWL 35ff.). The normative dimension of meaning is also one central message of Wittgenstein's famous comparison of language to a game like chess (PI \$108). On the one hand, like a chess-piece a token-word is a physical

3 In this context, 'correct' does not mean true but rather something like meaningful. This calls forth the spectre of circularity. Glock 2018 attempts to dispel it in a way that parallels section 10 below, namely by invoking connective analysis. It also defends the normativity of meaning against other animadversions. 
phenomenon. On the other hand, one cannot explain either the significance of a chess-piece or the meaning of a word in purely physical terms. Yet the difference between a chess-piece and a simple piece of wood or a meaningful word and a meaningless sound is not that the former are associated with an abstract entity or with a process in a separate mental realm. Rather, it is that they have a role in a rule-guided practice.

Unfortunately, a normative restriction of the pertinent type of use only goes some way towards resolving an underlying difficulty. 'Use (of a linguistic expression)' is a wider term than '(linguistic) meaning.' In pursuance of a correct account of meaning, this observation needs to be sharpened. There are at least three pertinent divergences (Glock 1996b, pp. 207-10). First, the notion of use has a wider extension, in that it applies to expressions like proper names and certain exclamations ('tally-ho', 'abracadabra') to which the notion of linguistic meaning arguably does not apply. Secondly, 'use' is acceptable in a wider range of sentence-frames: the correct way of using a word can involve gestures or be fashionable, but this cannot be said of its meaning. Thirdly, not all aspects of the use of a term are relevant to its meaning.

This last difference applies equally to use conceived in normative terms. Thus synonymous expressions can have distinct (rule-guided) uses. 'Cop' and 'law enforcement agent' are arguably synonymous; 'cop' does not mean tough law enforcement agent, for instance. But while 'cop' should not be used in a legal document, for example, there is no such convention concerning 'law enforcement agent'. Consequently, meaning does not determine use. At the same time, use determines meaning not causally, but conceptually - just as for Frege sense determines reference (see PI \$\$139, 197; PPF $\$ \$ 250,303$ ). While sameness of meaning co-exists with difference of use, every difference in meaning entails a difference in use. Or, to use a technical term in a loose sense, meaning supervenes on use. Given the use of a word, we can infer its meaning without additional data, yet not vice versa. One cannot tell from a dictionary explanation of 'cop' whether the term is frequently and unproblematically employed, e.g. in British court rooms or whether in that surrounding it is rare and subject to censure. By contrast, one can write the dictionary entry on the basis of a full description of the term's employment. Put in terms of the orthodox division of semiotics, the pragmatics of an expression includes its semantics, yet without being exhausted by it.

In short, there are undeniable differences between the way we use 'meaning of a word' and the way in which we use 'correct way of using a word.' As a result, the identification of meaning and overall linguistic use faces a fatal dilemma. On the one hand, if all aspects of overall use are semantically relevant, it follows that the two expressions do not mean the same. On the other hand, if not all aspects of overall use are semantically relevant, the identification of meaning with overall use is equally mistaken, since matters of use exceed matters of meaning. 
At the same time, we can learn from the use of a word everything there is to its meaning; use remains the guide to meaning, and conceptual analysis, even of a revisionist kind, must start out from investigating linguistic use. The more modest version of the use theory leaves intact the methodological message that the meaning of expressions is to be established by looking at their use. Unfortunately, it does not remove the aforementioned problem, namely that the term 'use' in vacuo is too wide. But at least it brings the difficulty into sharper focus. We have settled for the idea that rule-guided use determines meaning, rather than being identical with it. A difference in meaning entails a difference in use, not vice versa. The paramount question therefore is: what aspects of our rule-guided linguistic practices are relevant to meaning; is there any aspect difference in which entails a difference in meaning?

\section{Function, Role and Combinatorial Possibilities}

There are various attempts to solve this problem. At least three of themverificationism, inferential role theory and the idea of speech-act potentialare Wittgensteinian in inspiration or at least spirit. Unfortunately, they tend towards an overly restrictive conception of semantic rules, or so I argue elsewhere (Glock 2018). The immediately appealing option is to retreat to the more general idea that the meaning of an expression is linked to its role or function as determined by rules. But where to go from there? Remember, semantic rules should treat, for instance, 'cop' as equivalent to 'law enforcement agent' while pragmatic rules permit use of the latter yet not of the former in court or in a legal document. Appeal to role or function will not by itself overcome the difficulty, since an expression can have different kinds of roles. To mention just a few: expressions can have syntactic, psychological, social, institutional, legal and aesthetic roles. Along a different parameter, expressions can have a role in an idiolect or a role in a lexicon, and these roles can coincide or come apart.

One way of pursuing the idea of role or function that addresses this difficulty hails from Wittgenstein himself. He was aware of the need to single out the conceptually/semantically relevant aspects of our linguistic practices, to separate the 'essential' from the 'inessential' ones (RPP I \$666). Commenting on a fictional language in which one and the same type of tool is called differently on different days of the week, he claims 'not every use is a meaning.' He suggests that what guarantees a difference in meaning is a difference in the function of the word, but admits that this idea is itself imprecise (LW I \$289; see $\$ \$ 278-304$; BT 152; LPP 291). He takes a first step in putting flesh on it by recognizing that what matters is not the function an expression has in a particular context of utterance or within the idiolect of an individual speaker, but function as conferred by rules governing a 
whole language or linguistic community. Thus he explains both the sense of sentences and the meaning of words by reference to their 'place', 'role', 'purpose', or 'function' within an overall linguistic system or 'grammar' in his parlance (see BB 5; PG 59-63; OC \$64).

But expressions have distinct types of roles even within a linguistic system, to wit: syntactic, morphological, semantic and pragmatic roles. Now, the syntactic dimension is intimately connected to the semantic one. The Tractatus recognized this connection. The 'rules of logical syntax' determine the combinatorial possibilities of terms. They specify for any given lexical element or (logically proper) 'name' with what other names it can be combined into elementary propositions with a sense. Yet they do so without talking about the relation between the name and the (simple) 'object' it stands for.

Rules of logical syntax specify with what other expressions a given one can combine to yield a sequence of signs that is not just grammatically wellformed (like Chomsky's 'semantic anomalies', such as 'Colorless green ideas sleep furiously'), but has a sense. Such rules are crucial to any workable use theory. According to an influential line of criticism, such theories are incapable of explaining complex sentences, since ways of using and conceptual roles are not 'compositional' (Fodor and Lepore 1991). For instance, the respective ways of using the expressions 'the', 'cow', 'is', and 'radioactive', do not determine the way of using 'The cow is radioactive.' Fortunately, a use theory is not committed to the erroneous claim that there are semantic rules not just for how words are to be used but also for how complex sentences are to be used. Semantic rules of use concern lexical items. At the same time, these rules specify, inter alia, how the item can be used within sentences and what contribution it makes to the latter's senses. Someone who has mastered the use of "cow" knows, among other things, that: a) it is the name of a kind of animal; b) such a name can be combined with the definite article to form a singular term referring to a particular specimen; c) this singular term can in turn combine with the copula and an adjective to characterize the specimen it refers to. Someone who has mastered the adjective 'radioactive' knows, inter alia, that it can be meaningfully combined with singular terms referring to spatio-temporal objects, yet not with singular terms referring, e.g., to numbers, events or character traits. This is one of several respects in which the link between meaning and understanding (see section 10) props up a use theory.

\section{Form of Life Holism}

The Tractatus notwithstanding, however, confining semantic rules to those of logical syntax for the meaningful combination of words is too restrictive. The mere ability to manipulate symbols does not suffice for understanding, as Searle's Chinese Room Argument shows. Furthermore, there could be rules for combining words without either these words or the resulting 
combinations being meaningful, for instance in a play of words. In this respect, Wittgenstein's analogy between language and a game breaks down. Still, the difference between a meaningful use of $e$ and a mere game involving $e$ does not lie in the former being based on a connection between $e$ on the one hand, and either mental processes or abstract entities on the other. It lies rather in meaningful uses of $e$ being embedded in a practice. In a languagegame, linguistic and non-linguistic actions are interwoven. Both are also embedded in the environment, notably through perception. As a result, unlike mere word-plays bona fide linguistic acts have a role or purpose within a 'form of life' (PI \$273; see also Waismann 1965, pp. 158-9).

Alas, in developing this insight, the later Wittgenstein often errs in the opposite direction. Taking Frege's context-principle to extremes, he maintains that 'to imagine a language is to imagine a form of life' and that the meaning of a word is determined by its 'role in the whole life of a tribe' (EPB 149; see also e.g. RPP II $\$ \$ 16,77)$. Admittedly, it may well be necessary to consider the overall role of a concept in a form of life for (certain) philosophical purposes. Nevertheless, a word's social role is not a determinant of word-meaning. The point is most palpable in the case of expletives. Sexual swear words have the same role in some linguistic communities as sacrilegious or fecal ones in others. But for the benefit of my readers, I shall refrain from laboring this case. More generally, the conditions something must fulfill to fall under a general term-the features it must possess-are crucial to its meaning. Now, the things possessing these features can obviously change their social role, without the application conditions and hence the meaning of the term being affected. And in some cases the new role of those instances of the term draws in its wake a new role for the term itself. Consider the contrast between two developments in the overall usage of a single expression. 'Gay' acquired a new meaning when it came to be used as a synonym for 'homosexual.' But that meaning has not changed since then simply because, mercifully, most of us now have learnt to use the term freely and without negative connotations.

\section{Meaning, Explanation, and Understanding}

We have reached an impasse and need to pursue an alternative route. It exploits an unduly neglected aspect of Wittgenstein's reflections on meaning. The general idea is to elucidate the notion of meaning indirectly, through its conceptual connections to other pertinent notions (see Baker and Hacker 1980/2009, ch. II; Glock 2010, pp. 315-9). More specifically, Wittgenstein focuses on the connections between meaning on the one hand, and the explanations and understanding of specific expressions on the other.

'The meaning of a word is what the explanation of meaning explains.' I.e. if you want to understand the use of the word 'meaning', look at what is called 'explanation of meaning' (PI \$560). 
Prima facie, this is uninformative. If someone were to clarify what etymology is by saying that it is the history of an expression and then proceed with 'the history of an expression is what the explanation of its history explains', wouldn't we regard that as a rather tired joke? Similarly, for 'The American Constitution is what the explanation of the American Constitution explains.' But compare this last case to 'The British Constitution is what the explanation of the British Constitution explains.' This contrast indicates that a triviality can refer to more or less important and even essential aspects; the sentence just quoted does so for the nature of the British Constitution, Philosophical Investigations $₫ 560$ for the nature of meaning. Simplifying somewhat: unlike the US constitution, the British constitution is nothing other than, nothing over and above what is explained by British courts. Mutatis mutandis for the meaning of an expression: it does not have an existence independently of the expression being explained, used and understood. That is why Investigations $\$ 560$, though literally trivial, captures an essential feature of meaning.

To home in on this feature, one needs to follow up the truism with further elucidations. The first of these is that the explanation at issue is not causal. The explanation which is connected to meaning in a way that is both conceptual and illuminating is not an explanation why (an expression $e$ means what it does). Instead it is an explanation what (e means) by way of explaining how ( $e$ is to be used).

There are three meta-semantic lessons. First, the meaning of 'meaning' is connected to that of 'explanation.' Secondly, the truism reinforces the claim meaning has a normative dimension, since semantic explanations have a normative status. They function as standards of semantic correctness and competence. Thirdly, as regards the proper way for determining the meaning of specific expressions: if you want to know which rules for $e$ are semantic, look at which rules are invoked to explain the meaning of $e$.

Does that solve the problem of distinguishing semantic from other rules? Up to a point. Acceptable (notably lexical) explanations of 'cop' distinguish conditions of correct application from, inter alia, characterizations of legal legitimacy and social propriety. This is evident from, among other things, the entries in standard lexica. The explanans of such an entry explains or specifies the meaning of the explanandum at the start of the entry. That explanans will specify conditions of application, but not other rules concerning the explanandum. To be sure, after the explanandum there may be additional information about its use in parentheses. Some of these will be syntactic or morphological, for example, '(adj.).' But others will specify features of use that qualify as pragmatic, for instance, '(colloq.)' or '(pej.)' or '(anc.).' Even a parenthesis of that kind, however, falls short of specifying specific rules concerning the impropriety of 'cop' in a legal context. This is another respect, therefore, in which following up our apparently stale truism is illuminating: lexica provide a well-established, clear, and generally reliable, though by no 
means fail-safe, way of distinguishing semantically pertinent from other features of use.

Wittgenstein's strategy for clarifying meaning also appeals to how competent speakers understand an expression. The meaning of $e$ cannot transcend the understanding of competent speakers. That is to say, it cannot be at odds with explanations of that meaning which competent speakers are capable of proffering on reflection or at least capable of accepting when they are formulated by experts. Meaning is immanent rather than 'hidden' (see PI $\$ \$ 126-128)$. It is determined by how competent speakers understand $e .{ }^{4}$ The connection of meaning to semantic competence and knowledge of meaning furnishes a second way of demarcating semantic rules: to single out semantic rules consider whether a speaker needs to be familiar with them to count as a competent user, in the sense of knowing what $e$ means. Like the connection to explanation, it also highlights a normative aspect: competent speakers, users, or uses are those satisfying certain standards.

\section{Connective Analysis}

We have arrived at the following two conceptual connections:

Meaning-Explanation $(M E)$ : The linguistic meaning of an expression $e$ is what the explanation of $e$ (as opposed to an explanation of the phenomena $e$ refers to or applies to) explains.

Meaning-Understanding $(M U)$ : The linguistic meaning of an expression $e$ is what a competent speaker or user of $e$ (as opposed to someone who knows everything about the phenomena $e$ refers to or applies to) understands by $e$.

Both $M E$ and $M U$ provide criteria for identifying rules as semantic in a particular language. Alas, it is blatantly obvious that appeal to these criteria does not provide a non-circular explanation of what 'meaning' means. For in the sense pertinent to $M E$, 'explanation' must be understood as explanation of meaning, whether directly ('what the explanation of meaning explains') or indirectly ('as opposed to causal explanations...', etc.). Mutatis mutandis for $M U$ and 'understanding. The attempt to single out semantic rules appeals to conventions that can only be separated from other rules governing language by presupposing the notion of meaning. It would appear that the desideratum of demarcating semantic from other rules and the desideratum of analyzing the concept of meaning are mutually exclusive. Putting the point without reference to rules, Davidson complains: 'It is empty to say that meaning is use unless we specify what use we have in mind, and when we do specify, in a way that helps with meaning, we find ourselves going in a circle' (2005, p. 13).

4 This claim needs to be defended against externalist approaches to semantics like those of Kripke, Putnam and Burge. See Glock 2017a. 
At this juncture we should appeal to a distinct conception of conceptual analysis. Strawson distinguishes between 'atomistic', 'reductive', and 'connective' analysis (Strawson 1992, Chapter 2). Atomistic analysis seeks to break down concepts and propositions into components that are absolutely simple. Strawson repudiates atomistic analysis as 'distinctly implausible' (1992, p. 20). Reductive analysis tries to explain complex concepts in terms that are regarded as more perspicuous or less problematic from an empiricist or naturalistic perspective. Strawson resists this ambition on the grounds that the fundamental concepts with which descriptive metaphysics deals 'remain obstinately irreducible, in the sense that they cannot be defined away, without remainder or circularity, in terms of other concepts' (1995, p. 16). Strawson is right on both counts. Atomistic and reductive analysis seeks to break down concepts into simpler (in the case of atomistic analysis, ultimate) components and to unearth the concealed logical structure of propositions. Developments in the wake of the later Wittgenstein and of Quine (see, respectively, Glock 1996a; pp. 102-7; 203-8, 269-74 and Glock 2003; chs. 6-7) cast doubt on the quest to find simpler let alone ultimate semantic components for all our expressions.

We have good reasons, therefore, to abandon the idea that philosophical analysis decomposes or dismantles a complex phenomenon, and thereby the analogy to chemical analysis. Strawson's alternative-connective analysisis the description of the rule-governed use of expressions, and of their connections with other expressions by way of implication, presupposition, and exclusion. It need not result in definitions; instead, it can instead rest content with elucidating features which are constitutive of the concepts under consideration, and with establishing how they bear on philosophical problems, doctrines, and arguments. ${ }^{5}$

We were faced with a circularity involved in explaining meaning by reference to rules to be demarcated from other rules by appeal to linguisticsemantic explanation and understanding. But all explanations of meaning eventually move in a circle, either directly or indirectly. What is to be avoided is not explanatory circles per se, but rather those that are too narrow or unilluminating for other reasons. The circles-in turn interconnectedsummarized by $M E$ and $M U$, respectively, are not of this kind. They shed light on the problematic notion of meaning by reference to notions that do not invite reification and which are less confusing in philosophical contexts. Both also highlight normative dimensions of the concept of meaning of the kind that Wittgenstein was rightly keen on.

5 Strawson not only articulated the method of connective analysis which vindicates the appeal to MU and ME, he also anticipated ME through his claim that 'to give the meaning of an expression ... is to give general directions of its use' (1971, p. 9). I am grateful for an anonymous referee for reminding me of this passage. 


\section{And the Methodological Moral of the Story?}

Establishing the lexical meaning of philosophically troublesome expressions by way of describing their function in our linguistic practices is crucial to Wittgenstein's later philosophizing. The antidote to conceptual confusions is grammatical reminders of how we use words outside philosophy-'It makes sense to say "I know that she has toothache" or 'A dog cannot be said to believe that its master will return in a week'. These are articulations of rules that we have been following all along. Their point is to draw attention to the violation of grammar by philosophers. They are part of a dialectical critique of sense, an 'undogmatic procedure' which contrasts with the dogmatic insistence of the Tractatus that only certain combinations of signs can make sense because of the constraints imposed by the picture theory (WVC 1836; see PR 54-5; PI \$\$89-90, 127; BT 419, 424-5 and below). Wittgenstein tries to show that his interlocutors use words according to conflicting rules, without relying on contentious views of his own.

Wittgenstein and his followers have provoked the complaint of setting themselves up as 'guardians of semantic inertia' (Gregory 1987, pp. 242-3) who criticize philosophical and scientific theories as confused simply because they diverge from ordinary use. These complaints ignore that by 'ordinary use' they do not necessarily mean everyday use; instead, they mean established use, whether it be in common parlance or in technical forms of discourse with a tightly regimented vocabulary (Ryle, 1971, ch. 23). Thus, Wittgenstein does not extol the virtues of everyday over technical language, or of the mundane everyday over the sophisticated specialized employment of a term. Nor does he prohibit the introduction of technical terminology in either science or philosophy. He refrains explicitly from criticizing philosophical positions merely for violating 'common sense' (BB 48-9, 58-9) or for employing novel terms or familiar words in ways that differ from the established patterns of use (see PI \$254; RPP I \$548; RPP II §289; LPP 270).

Rather, Wittgenstein insists that such novel terms or uses need to be adequately explained by laying down clear rules. He further alleges that metaphysical questions and theories-no matter whether propounded inside or outside of the academic discipline philosophy_-get off the ground only because they employ terms in a way which is at odds with their official explanations, and that they trade on deviant rules along with the ordinary ones. In effect, Wittgenstein tries to confront metaphysicians with a trilemma: either their novel uses of terms remain unexplained (unintelligibility), or it is revealed that they use expressions according to incompatible rules (inconsistency), or their consistent employment of new concepts simply passes by the ordinary use-including the standard use of technical termsand hence the concepts in terms of which the philosophical problems were phrased (ignoratio elenchi). 
In a similar vein, Ryle intimated that conceptual analysis is interested less in language as a system (de Saussure's langue), than in the often obscure, slippery and equivocal uses (parts of de Saussure's parole) to which it is put in the course of a specific line of reasoning (1971: chs. 14, 24, 31). To that extent, philosophical method takes note of speaker's meaning as well as of lexical meaning. Its dialectical business involves drawing attention to the relations between the two in the context of philosophical investigations, including investigations outside of academic philosophy that have a conceptual dimension.

\section{The Myth of Mere Method}

So far so good. Connective analysis à la Wittgenstein, Ryle and Strawson can elucidate the notion of linguistic meaning without vicious circularity; it thereby underpins conceptual elucidation as a dialectic philosophical method. But this line of thought involves a different type of circularity, however. It concerns not the explanation of semantic notions but the justification of a metaphilosophical view. On the one hand, Wittgenstein's conception of philosophy as connective analysis relies on an understanding of meaning as determined by rules of use. On the other hand, this understanding is in turn arrived at by way of connective analysis.

Wittgenstein was aware of this problem. Alas, his attempts to solve it fail. In his early work, at least, he succumbed to what one might call the myth of mere method. This is the illusion that one can fashion philosophical methods in a presuppositionless manner, one which does not in turn draw on philosophical views, e.g. about logical necessity, linguistic meaning or the nature of philosophical problems. In the Tractatus the method, in particular an ideal notation for the analysis of propositions, is supposed to be put in place by propaedeutic claims about the essence of representation that are then disowned as nonsensical. In the Investigations it seems that the method and the metaphilosophical remarks describing it are supposed to emerge automatically as a spin-off from reflections on specific philosophical problems. But the Tractatus procedure is self-refuting; and the philosophical problems discussed in the Investigations only cry out for Wittgenstein's treatment on a certain understanding of their nature, an understanding which itself is philosophically contentious.

Consider just one looming circularity. Wittgenstein entreats us to address philosophical problems by looking at non-philosophical linguistic use. That recommendation depends on two ideas: the content of these problems (their constitutive concepts) is determined by the linguistic meaning of the expressions involved; and that meaning is a function of their use. These ideas are in turn supported by observations concerning the non-philosophical use of 'meaning', its cognates and related notions like that of what is said or 
asked. We have reason to condone this particular circle, since it is difficult to envisage a better starting-point for clarifying or even modifying a notion like meaning than its established use. Nevertheless, in urging that point one cannot boot-strap oneself onto a privileged methodological plane immune to controversy.

The nature of philosophy is itself a contested philosophical issue, and views about this issue are philosophically controversial. The label 'metaphilosophy' notwithstanding it is not a distinct higher-order discipline, but an integral part of philosophy itself. One of his followers, Lazerowitz (1964/2004), theorized about philosophy from the external vantage point of psychoanalysis; yet thereby failed to address the philosophical issue of what philosophy is and should be. By contrast, Wittgenstein himself recognized this point (PI \$121). Once it is acknowledged that one cannot engage in metaphilosophy without doing philosophy, however, the myth of mere method collapses. One cannot swim without venturing into the water. And one cannot address philosophical problems, the nature of philosophy included, without doing philosophy, and hence without philosophical arguments and commitments of one's own. What one can do is to ensure consistency between philosophical methods, metaphilosophical and substantive views, and to argue for all of them in as plausible and unassuming a way as possible. The notion of linguistic meaning ought to play a central role in this kind of argument. ${ }^{6}$

\section{References}

Baker, G.P. and Hacker, P.M.S. 1980/2009. Wittgenstein: Understanding and Meaning. Volume 1 of an Analytical Commentary on the Philosophical Investigations. Part 1. Essays. Second edition. Extensively revised by P.M.S. Hacker. Oxford: Wiley-Blackwell.

Baker, G.P. and Hacker, P.M.S. 1984. Language, Sense and Nonsense. Oxford: Blackwell.

Crystal, David 1987. The Cambridge Encyclopedia of Language. Cambridge: Cambridge University Press.

Davidson, Donald 1984. Inquiries into Truth and Interpretation. Oxford University Press.

Davidson, Donald 2005. Truth, Language, and History: Philosophical Essays. Oxford: Clarendon Press.

Dummett, M.A.E. 1978. Truth and other Enigmas. London: Duckworth.

Dummett, Michael 1993a. The Origins of Analytical Philosophy. London: Duckworth.

6 I am grateful to Pit Genot for assistance, to an anonymous referee for comments, and to Slobodan Perović for his encouragement and patience. 
Dummett, Michael 1993b. 'What Does the Appeal to Use Do for the Theory of Meaning', in The Seas of Language, 106-116. Oxford: Oxford University Press.

Fodor, Jerry and Lepore, Ernest 1991. 'Why Meaning (Probably) Isn't Conceptual Role', Mind \& Language 6: 328-343.

Glock, Hans-Johann 1996a. A Wittgenstein Dictionary. Oxford: Blackwell.

Glock, Hans-Johann 1996b. 'Abusing Use', Dialectica 50: 205-223.

Glock, Hans-Johann 2003. Quine and Davidson on Language, Thought and Reality. Cambridge: Cambridge University Press.

Glock, Hans-Johann 2006. 'Tractatus Logico-Philosophicus'. In J. Shand (ed.), Central Works of Philosophy Vol. 4, 71-91. Chesham: Acumen.

Glock, Hans-Johann 2010. 'Concept: Between the Subjective and the Objective'. In John Cottingham and P.M.S. Hacker (eds.), Mind, Method and Morality: Essays in Honour of Anthony Kenny, 306-329. Oxford: Oxford University Press.

Glock, Hans-Johann 2017a. 'Impure Conceptual Analysis'. In Guisseppina D'Oro and Søren Overgard, The Cambridge Companion to Philosophical Methodology, 77-100. Cambridge: Cambridge University Press.

Glock, Hans-Johann 2017b. 'Philosophy and Philosophical Method'. In Hans-Johann Glock and John Hyman (eds.), The Blackwell Companion to Wittgenstein, 231-251. Marsden: Wiley.

Glock, Hans-Johann 2018 [Forthcoming]. 'What is Meaning? A Wittgensteinian Answer to an UnWittgensteinian Question'. In S. Greve and J. Conant (eds.), Wittgenstein on Objectivity, Intuition, and Meaning. New York: Cambridge University Press.

Gregory, R.L. 1987. 'In Defense of Artificial Intelligence-A Reply to John Searle'. In C. Blakemore and S. Greenfield (eds.). Mindwaves, 234-244. Oxford: Blackwell.

Hanfling, Oswald 2000. Philosophy and Ordinary Language. London: Routledge.

Hanfling, Oswald 2004. 'The Use of "Theory" in Philosophy'. In Erich Ammereller and Eugen Fischer (eds.), Wittgenstein at Work: Method in the Philosophical Investigations, 183-200. London: Routledge.

Horwich, Paul 2005. Reflections on Meaning. Oxford: Oxford University Press. Lazerowitz, Morris 1964/2004. Studies in Metaphilosophy. London: Routledge.

Quine, W.V.O. 1953. From a Logical Point of View. Cambridge, Mass.: Harvard University Press. 
Quine, W.V.O. 1969. Ontological Relativity and Other Essays. New York: Columbia University Press.

Quine, W.V.O. 1981. Theories and Things. Cambridge, Mass.: Harvard University Press.

Rundle, Bede 1990. Wittgenstein and Contemporary Philosophy of Language. Oxford: Blackwell.

Ryle, Gilbert 1971. Collected Papers. Volume II. London: Hutchinson.

Schroeder, Severin 2006. Wittgenstein. Cambridge: Polity.

Strawson, P.F. 1963. 'Carnap's Views on Constructed Systems vs. Natural Languages in Analytic Philosophy'. In Paul Schilpp (ed.), The Philosophy of Rudolf Carnap. Library of Living Philosophers, Vol. XI, 503-518. La Salle Ill.: Open Court.

Strawson, P.F. 1971. Logico-Linguistic Papers. London: Methuen.

Strawson, P.F. 1992. Analysis and Metaphysics: An Introduction to Philosophy. Oxford: Oxford University Press.

Strawson, P.F. 1995. 'My Philosophy', in Pranab Kumar Sen and Roop Rekha Verma (eds.), The Philosophy of P.F. Strawson, 1-19. New Delhi: Allied Publishers.

Waismann, Friedrich. 1965. The Principles of Linguistic Philosophy. Ed. R. Harré. London: Macmillan.

Wittgenstein, Ludwig. Tractatus Logico-Philosophicus [1922] 1961 [=TLP]. Trans. D.F. Pears and B.F. McGuinness. London: Routledge and Kegan Paul.

Wittgenstein, Ludwig. Culture and Value [1977] 1998 [=CV]. Ed. G.H. von Wright in collaboration with $\mathrm{H}$. Nyman. Revised edition of the text by A. Pichler. Trans. P. Winch. Oxford: Blackwell.

Wittgenstein, Ludwig. Philosophical Remarks [1929-1930] 1975 [=PR]. Ed. R. Rhees. Trans. R. Hargreaves and R. White. Oxford: Blackwell.

Wittgenstein, Ludwig. Philosophical Grammar [1932-1934] 1974 [=PG]. Ed. R. Rhees. Trans. A.J.P. Kenny. Oxford: Blackwell.

Wittgenstein, Ludwig. The Big Typescript: TS 213 [1933] 2005 [=BT]. Ed. and trans. C.G. Luckhardt and M.A.E. Aue. Chichester: Wiley-Blackwell.

Wittgenstein, Ludwig. The Blue and Brown Books [1933-1935] 1958/1969 $[=B B]$. Ed. R. Rhees. Second edition. Oxford: Blackwell.

Wittgenstein, Ludwig. Eine philosophische Betrachtung [1936] 1970 [=EPB]. Ed. R. Rhees. In Schriften, Vol. 5, 117-282. Frankfurt: Suhrkamp. 
Wittgenstein, Ludwig. Remarks on the Foundations of Mathematics [19371944] 1956/1978 [=RFM]. Ed. G.H. von Wright, R. Rhees and G.E.M. Anscombe. Trans. G.E.M. Anscombe. Third, revised, and reset edition. Oxford: Blackwell.

Wittgenstein, Ludwig. Philosophical Investigations [1953] 2009 [=PI]. Ed. G.E.M. Anscombe and R. Rhees. Fourth, revised edition by P.M.S. Hacker and J. Schulte. Trans. G.E.M. Anscombe, P.M.S. Hacker and J. Schulte. Oxford: Wiley-Blackwell.

Wittgenstein, Ludwig. Philosophy of Psychology - A Fragment [1946-1949]. In PI, 2009, pp. 183-243. Ed. P.M.S. Hacker and J. Schulte. Trans. G.E.M. Anscombe, P.M.S. Hacker and J. Schulte.

Wittgenstein, Ludwig. Remarks on the Philosophy of Psychology, Vol. 1 [19451947] 1980 [=RPP I]. Ed. G.E.M. Anscombe and G.H. von Wright. Trans. G.E.M. Anscombe. Oxford: Blackwell.

Wittgenstein, Ludwig. Remarks on the Philosophy of Psychology, Vol. 2 [1948] 1980 [=RPP II]. Ed. G.H. von Wright and H. Nyman. Trans. C.G. Luckhardt and M.A.E. Aue. Oxford: Blackwell.

Wittgenstein, Ludwig. Zettel. [1945-1948] 1967 [=Z]. Ed. G.E.M. Anscombe and G.H. von Wright. Trans. G.E.M. Anscombe. Oxford: Blackwell.

Wittgenstein, Ludwig. Last Writings on the Philosophy of Psychology, Vol 1 [1948-1949] 1982 [=LW I]. Ed. G.H. von Wright and H. Nyman. Trans. C.G. Luckhardt and M.A.E. Aue. Oxford: Blackwell.

Wittgenstein, Ludwig. On Certainty. [1951] 1969/1974 [=OC]. Ed. G.E.M. Anscombe and G.H. von Wright. Trans. D. Paul and G.E.M. Anscombe. Oxford: Blackwell.

Wittgenstein, Ludwig. Wittgenstein and the Vienna Circle: Conversations recorded by Friedrich Waismann. [1929-1932] 1979 [=WVC]. Ed. and trans. B.F. McGuinness. Oxford: Blackwell.

Wittgenstein, Ludwig. Wittgenstein's Lectures, Cambridge 1930-32, From the Notes of J. King and D. Lee. 1980 [=LWL]. Ed. D. Lee. Oxford: Blackwell.

Wittgenstein, Ludwig. Wittgenstein's Lectures, Cambridge 1932-35, From the Notes of A. Ambrose and M. MacDonald. 1979 [=AWL]. Ed. A. Ambrose. Oxford: Blackwell.

Wittgenstein, Ludwig. Wittgenstein's Lectures on the Foundations of Mathematics, Cambridge 1939, From the Notes of R.G. Bosanquet, N. Malcolm, R. Rhees and Y. Smythies. 1976 [=LFM]. Ed. C. Diamond. Sussex: Harvester.

Wittgenstein, Ludwig. Wittgenstein's Lectures on Philosophical Psychology 1946-47, Notes by P.T. Geach, K.J. Shah, and A.C. Jackson. 1988 [=LPP]. Ed. P.T. Geach. Sussex: Harvester. 
Wittgenstein, Ludwig. Wittgenstein's Nachlass: The Bergen Electronic Edition. 2000. Ed. the Wittgenstein Archives at the University of Bergen. Oxford: Oxford University Press. [References to Wittgenstein's manuscripts and typescripts are by MS or TS number, following G.H. von Wright's catalogue (see G.H. von Wright, Wittgenstein, 1982. Oxford: Blackwell, pp. 35 ff.)]. 